\title{
ELEMENTOS INICIAIS PARA UMA CRÍTICA DA FORMAÇÃO PROFISSIONAL SUPERIOR INSPIRADA PELOS DISPOSITIVOS DA ESCOLA DE LACAN E A FORMAÇÃO DO ANALISTA
}

\section{Roberto Henrique Amorim de Medeiros}

\author{
Roberto Henrique \\ Amorim de Medeiros \\ Universidade Federal \\ do Rio Grande do Sul \\ (UFRGS), Professor \\ Adjunto do \\ Departamento de \\ Assitência e \\ Orientação \\ Profissional, \\ Bachalerado em Saúde \\ Coletiva e do \\ Programa de Pós- \\ Graduação em \\ Psicanálise: clínica e \\ cultura, Porto \\ Alegre/RS, Brasil
}

RESUMO: O artigo procura fomentar debate acerca da formação do psicanalista, por meio do resgate da história e dos elementos fundamentais da Escola Freudiana de Psicanálise, fundada por Lacan. Por fim, discute as possíveis contribuições lacanianas à formação do analista e propõe que os discursos circulantes na Escola e seus dispositivos também possam constituir analisadores para pesquisas sobre o problema da formação baseada em treinamento e reprodução técnica em profissões cujo objeto é o outro e o sofrimento humano.

Palavras-chave: psicanálise; Jacques Lacan; Escola de Psicanálise; formação do analista; formação profissional.

ABSTRACT: Initial elements for a critique of the superior professional formation inspired by the devices of the School of Lacan and the formation of the analyst. The article seeks to foment debate about the formation of the psychoanalyst, through the rescue of history and the fundamental elements of the Freudian School of Psychoanalysis, founded by Lacan. Finally, it discusses the possible Lacanian contributions to the analyst's formation and proposes that the circulating discourses in the School and its devices may also be analyzers for researches on the problem of formation based on training and technical reproduction in professions whose object is the other and human suffering.

Keywords: Psychoanalysis; Jacques Lacan; School of Psychoanalysis; training analyst; professional qualification.

DOI - http://dx.doi.org/10.1590/S1516-14982018002013

Todo o conteúdo deste periódico, exceto onde estiver identificado, está licenciado sob uma Licença Creative Commons (cc by 4.0) 
$\mathrm{D}$ eterminar os processos aos quais se possa atribuir a qualidade de formação de uma pessoa é uma tarefa impraticável, pois tende ao infinito. Enumerar, porém, aqueles avalizados por um documento legal, chamado diploma, que thes confere efetividade pública, seria uma tarefa enfadonha, embora possível. 0 reconhecimento efetivo a outros tipos de formação é muito pouco, não obstante sejam encarados como fundamentais e necessários. Por exemplo, para a formação do cidadão, há grande valorização do papel da família, da cultura, das viagens e do poliglotismo, mas de pouco valem qualquer desses elementos para que possa usufruir das habilidades desenvolvidas com as experiências de sua vida e, assim, obter dinheiro pela prestação de serviços. Muitos seriam os acusados de falsidade ideológica e charlatanismo se propusessem serviços a partir de sua experiência como filho, viajante, leitor ou amigo, entre outras.

Entretanto, talvez haja, sim, uma profissão que, na sua origem e essência, não se autoriza suficientemente a partir de uma formação acadêmica, diplomas, mas que, em alguns países, parece gozar de status semelhante, pois possui reconhecimento formal, legal e mesmo científico; com algumas restrições, é bem verdade.

Refiro-me aos psicanalistas. Porém, como se faz para tornar-se um deles? Desde Freud, poucos psicanalistas debruçaram-se tanto sobre esse tema quanto Jacques Lacan. Com o tempo, a formação do analista se aproximou ao modo acadêmico, organizado pelos dispositivos do discurso universitário (LACAN, 1969-1970/1992). A instituição criada por Freud, a IPA (sigla em inglês para Associação Psicanalítica Internacional) tentou normalizar um processo sustentado no tripé análise pessoal, estudo e supervisão, para que um aspirante a psicanalista pudesse assim ser autorizado.

Na década de 1950, na França, ocorreu uma primeira cisão importante na história do movimento psicanalítico (MARINI, 1990), que vai resultar no surgimento de uma proposta de formação de analistas estruturada sob outro discurso, o analítico. Em 1964, no seio do movimento psicanalítico francês, teve-se notícia da criação de uma escola. Atente-se para o termo: uma escola. Não uma sociedade, uma associação, um sindicato ou corporação, mas uma escola: local coletivo de aprendizagem primeira. Um local de passagem, de transmissão.

Lacan, psicanalista francês, após jamais ter sido aceito como filiado à IPA e ter sua prática como psicanalista e formador questionada, criou uma escola que, em seus pressupostos organizativos e modos de ingresso, valorizava aspectos essenciais da obra freudiana. $\mathrm{O}$ anúncio da fundação da Escola Freudiana de Paris (EFP) vem acompanhado da enunciação lacaniana: o analista deve autorizar-se de si mesmo. Alguns anos mais tarde, o próprio Lacan acrescentaria a continuação: e de alguns outros, quando, em sua Proposição, de 9 de outubro de 1967, instaurara o dispositivo do Passe.

O analista se autoriza de si mesmo e de alguns outros é, sem dúvida, uma frase de efeitos que abalavam um lugar de poder a respeito de quem poderia ou não exercer a psicanálise e nem sempre bem interpretada, mesmo no meio psicanalítico. Porém, um enunciado fértil, por revelar uma ética de formação que: a) responsabiliza diretamente o sujeito através de seu desejo de tornar-se analista; b) indaga o sujeito acerca de sua preparação para enfrentar os problemas da profissão; e c) elide uma desresponsabilização do sujeito em atribuir sua capacidade ao conhecimento dos mestres ou da ciência à qual se filiou, ao mesmo tempo em que não deixa de referenciar aos outros o reconhecimento da conclusão de sua formação.

Afinal, que tipo de escola é essa que, para ser admitido, o aluno deve manifestar seu desejo por meio de uma questão de estudo a ser compartilhada e desenvolvida com seus pares, ao invés de envolver-se numa competição com eles? Que escola pode ser esta na qual não é o acúmulo de créditos, através do quantitativo de frequência e aproveitamento em relação às disciplinas cursadas, o que vai avalizar a formação? Por fim, que escola nem dá garantias ao aluno quanto a conseguir o título que busca?

Por meio de diversos documentos históricos sobre o percurso do psicanalista Lacan - livros, artigos, romances, revistas científicas e demais escritos (DORGEUILLE, 1986; GIROUD et al., 2002; JORGE, 2006; 
DIDIER-WEILL et al., 2007) - e depoimentos de seus contemporâneos, alunos e/ou analisantes, é possível afirmar que essa escola foi a EFP, fundada em 21/7/1964 e dissolvida em 11/3/1980 (LACAN, 2003).

Pergunta-se: considerando que o trabalho com a formação do analista compreendeu boa parte dos seus esforços teóricos e práticos, e tendo sido um pesquisador de ponta acerca da transmissão de um saber, é possível inspirar-se em Lacan e suas propostas de escola para refletir criticamente acerca de outra ética de formação profissional em nível superior?

Propõe-se que o caminho para uma resposta à questão se dê nos trilhos da história da Psicanálise depois de Freud, para que se possa evidenciar, em seguida, as características essenciais da pesquisa acerca do processo psicanalítico de formação e das propostas que sustentaram a ética e os dispositivos da EFP, assim como formulados por Lacan.

\section{A ESCOLA DE LACAN}

Freud estabeleceu os princípios do que veio a nomear Psicanálise a partir de uma experiência clínica sustentada por uma escuta incomum de seus pacientes. Embora tenha escrito alguns trabalhos introdutórios a respeito da prática analítica nascente (FREUD, 1912/1976; 1912 /1976a; 1913/1976), deixou aos seus sucessores a maior parte da pesquisa sobre a formação de analistas. Suas recomendações aos interessados em se tornarem psicanalistas acabaram por inspirar uma regra sustentada rigidamente pela IPA e seus grupos filiados ao redor do mundo, construída em torno da análise didática, da supervisão e da escuta de pacientes.

Numa vertente que se tornou conhecida por psicologia do ego, em voga a partir dos anos 1930, a análise teria por objetivos o reforço egóico do paciente a partir da identificação com o "ego forte" do analista, a conscientização do material inconsciente e a dominação das pulsões primitivas do id pelo ego. A IPA apenas reconheceria analistas que se submetessem a um tratamento padronizado: sessões de análise com frequência e tempo determinados - quatro a cinco vezes por semana com duração de 50 minutos - paciente na posição deitada sobre o divã e sob a escuta de um terapeuta abstinente, o que seria garantido por sua mudez durante as sessões.

Na Sociedade Psicanalítica de Paris (SPP), filiada à IPA, um médico psiquiatra passou a chamar atenção, alguns anos depois de seu ingresso em 1934, pelas suas posições críticas sobre os rumos da Psicanálise em seu tempo. Com teorizações consistentes sobre os textos freudianos, o psiquiatra Jacques Lacan (1901-1981) partiu do trabalho com pacientes psicóticos nos asilos de Saint-Anne, dos seus estudos sobre a paranoia e de sua leitura original da teoria freudiana, para questionar a intelligentsia psicanalítica da época e suas teorias sobre o ego. Dessa forma, promoveu o movimento que nomearia retorno a Freud, recolocando o foco no inconsciente e suas formações.

Segundo Roudinesco (1988), nesses anos circulavam três visões distintas sobre a formação em Psicanálise dentro da IPA: uma visão médica, comandada por Sacha Nacht, para quem a psicanálise servia como currículo útil à medicina; uma visão universitária, de Daniel Lagache, na qual a formação sustentava-se no estudo de disciplinas retiradas dos textos freudianos; e a escola inglesa, considerada menos rígida.

A opinião de Lacan era a de que as linhas do pensamento psicanalítico deveriam obedecer ao primado da descoberta freudiana: experiência discursiva na qual o ego é o que há de mais revogável na estrutura do sujeito. Sujeito, constituído pela linguagem, vinculado a uma falta primordial denominada castração que lhe permite o acesso ao desejo. Para ser analista o diploma universitário seria necessário, mas não suficiente.

Ao perguntar-se pela constituição da realidade e do ego ${ }^{1}$ e pesquisando a linguagem desde os idos de 1936, Lacan subverteu a produção teórica da época e atualizou a experiência freudiana, introduzindo a noção de sujeito do inconsciente com seu registro simbólico garantido pela palavra (MARINI, 1990).

\footnotetext{
${ }^{1}$ Em O Estádio do Espelho como formador da função do Eu e Para Além do princípio de realidade.
} 
Lacan observava que a reunião em torno da psicanálise deveria ser por uma transferência simbólica de trabalho - pesquisa e estudo - e não por uma identificação imaginária de classe na qual a formação é garantida pelo espelhamento ao mestre. Neste último caso, a reunião em torno do saber dá-se por uma associação corporativa que defende e assegura o direito da profissão, e o profissional sustenta-se muito mais por exercício de poder do que pela capacidade de adquirir e transmitir um saber.

O chamado Institut, dentro da SPP, era o lugar de ensino e formação dos analistas. Ali reinava a lógica universitária pela qual a transmissão se dava por meio de mestres que recitavam sua interpretação da obra de Freud para seus alunos.

Lacan criticava o caráter dogmático da formação e o empobrecimento da experiência analítica no sentido utilitarista e adaptativo. Em contrapartida, a mais recorrente das críticas contrárias a Lacan incidia sobre a duração variável das sessões de análise conduzidas por ele. A IPA, com suas normalizações do suposto bemfazer analítico, condenava o procedimento lacaniano embasado no tempo lógico ${ }^{2}$. A posição de Lacan entre seus colegas da instituição era constrangedora, na medida em que esta, embora já filiada à IPA, contava com um analista que não era aceito pela instituição maior.

No ano em que presidiu a SPP, Lacan tornou-se o primeiro a propor o estudo da psicanálise de crianças como essencial à formação dos analistas. Criticava duramente a literatura e a prática psicanalíticas de sua época, bem como as posições de membros da SPP que, em acordo com a IPA, negavam a formação analítica para não médicos (ROUDINESCO, 1988).

Segundo depoimentos de seus analisantes (DIDIER-WEILL et al., 2007, passim), a posição de Lacan frente ao que diziam seus pacientes em sessão era semelhante à de um pesquisador. Tudo lhe soava importante e como novidade a questionar o seu saber. Estava atento a outras áreas do conhecimento, como a antropologia, a matemática, a topologia e as novidades da época, como a linguística e o estruturalismo, naquilo que trouxessem soluções para os problemas surgidos do contexto da escuta psicanalítica.

A vontade aparentemente inesgotável de ser ouvido pelos seus colegas psicanalistas é amplamente atestada nas publicações que contêm depoimentos de seus contemporâneos, entre eles colaboradores, analisantes e alunos (idem; GIROUD et al, 2002; MARINI, 1990). Os testemunhos deixam perceber a importância que Lacan atribuía à necessidade do debate acerca da experiência psicanalítica, que, segundo ele, estava perdendo seu potencial de subversão devido aos usos instrumentais, tecnicistas e adaptativos pelos psicanalistas da época.

O esforço em manter vivo o ensino de Freud parece ter obrigado Lacan a pronunciar-se cada vez mais sobre a técnica e a teoria psicanalíticas e a sustentar seu retorno a Freud. Resumidamente, a finalidade de seu ensino era formar analistas para a escuta psicanalítica do sujeito, tomado como um efeito de significante e não como lugar determinado do indivíduo em relação às coisas do mundo. Algo latente em Freud, indicado pelas formações do inconsciente: os sonhos, os lapsos, o chiste.

A respeito da escuta analítica, Lacan apresentou no Congresso de Roma - 26 e 27 de setembro de 1953 - o posicionamento que embasa sua técnica e seu ensinamento, tão questionados. Antes de seu pronunciamento que ficara conhecido como o Discurso de Roma, Lacan havia distribuído cópias da sua exposição, na qual apresentava os efeitos do campo da linguagem na Psicanálise (LACAN, 1966/1998, p. 238324), tentando esclarecer e trazer para o debate a função da fala do analisante. Constituía-se na formalização teórica do profundo interesse e respeito que demonstrava Lacan com o lugar de enunciação dos seus analisantes, mais do que com o conteúdo do que diziam (DIDIER-WEILL et al., 2007). A preocupação com os rumos da prática analítica evidenciava-se na crítica ao reforço egóico. Um equívoco conceitual, na medida em que a descoberta freudiana indicava que o ego não é senhor em sua própria casa (FREUD, 1917/1976), o que

\footnotetext{
${ }^{2}$ Lacan formalizoou esta prática com o trabalho $O$ tempo lógico e asserção da certeza antecipada, originalmente publicado em Les cahiers d'Art, em 1945.
} 
levava a psicanálise a constituir-se numa prática funcionalista de adaptação a um ideal de normalidade, mais bem adaptado ao discurso e à ordem médica.

\section{AS CISÕES: FUNÇÃO DE CORTE}

Em 1953, a situação de Lacan na SPP tornou-se insustentável no momento em que foi convidado a se retirar da presidência e impedido de conduzir análises didáticas, ou seja, trabalhar com a formação de novos analistas. Lacan decide então desligar-se da SPP e funda, com Daniel Lagache e Françoise Dolto, a Sociedade Francesa de Psicanálise (SFP). Pela presença de Lacan, essa sociedade jamais seria reconhecida e afiliada à IPA.

Lacan organizou a nova sociedade através de um dispositivo. Seus aspirantes deveriam reunir-se em Grupos de Estudo de Psicanálise. Desde a conferência de abertura - sobre o RSI ${ }^{3}$, em 8 julho de 1953 - até sua saída dessa sociedade uma década depois, Lacan disparou uma série de artigos e pronunciamentos públicos pelo avanço na pesquisa psicanalítica. Especialmente através de seu Seminário ${ }^{4}$, esses atos promoveram uma incrível expansão do pensamento lacaniano nas rodas de psicanálise francesas e em outros países. Em alguns anos, Lacan surpreendentemente reuniu em torno de si um número maior de aspirantes a analistas do que a sociedade que abandonou.

A obstinação por reconhecimento pela IPA era um compromisso ético de Lacan, que, na primeira metade dos anos 1960, já reunia verdadeiras multidões nos dias em que proferia seus seminários abertos ao público 5 . Entretanto, durante os anos de 1961 a 1963, um comitê da representação da IPA, comandado pelo psicanalista Pierre Turquet, investigou a SFP com especial ênfase sobre as análises didáticas conduzidas por Lacan. 0 clima era inquisitório, segundo os depoimentos de analisantes de Lacan, e, particularmente, o interesse recaía na questão do tempo de duração das sessões (DIDIER-WEILL, 2007, passim). Ao final de seu trabalho, a Comissão Turquet deveria opinar quanto ao pedido de filiação da SFP à IPA. Descontente com seus métodos, mas reconhecedora de sua obra já solidificada na época, a comissão anunciou que Lacan poderia seguir apenas com seus seminários e sua prática clínica, mas seus analisantes não seriam reconhecidos como analistas.

Por sua excomunhão (LACAN, 1964/1988), Lacan é abandonado por muitos de seus alunos e analisantes. Sentiu que deveria deixar a SFP e criou, "tão sozinho como sempre esteve em relação com a causa psicanalítica" (LACAN, 2003, p. 235), como escrevera na época, a Escola Freudiana de Paris (EFP), que durou de 1964 até 1980 (ROUDINESCO, 1988). Estabelecia-se, assim, uma segunda cisão.

Lacan interrompeu seu seminário sobre os Nomes-do-Pai, e iniciou, no mesmo, ano Os quatro conceitos fundamentais da Psicanálise (LACAN, 1964/1988), na sala Dussane da École Normal Supérieure, na rua D’ulm, contando com o apoio de intelectuais como Althusser e Lévi-Strauss. A mudança do local do seu seminário para um meio acadêmico ampliou também o seu público. Passaram a escutar Lacan, filósofos, antropólogos e matemáticos, além dos psicanalistas.

Entre outros motivos, a criação da EFP cumpria o papel de não deixar os alunos e analisantes de Lacan solitários e sem recursos para sustentarem seu desejo pela psicanálise. A Escola propunha um ensino garantido pela insistência na retomada da leitura dos textos de Freud, de preferência em alemão, e através da inspiração na experiência do inconsciente: um saber não sabido, mas passível de transmissão e que pode ser fundamentado em uma lógica. $O$ modo de algum aspirante a analista constituir um lugar de formação na

3 Real, Simbólico e Imaginário, cuja sigla RSI em francês tem homofonia com a palavra heresia. Um título premonitório tendo em vista sua "excomunhão" pela IPA, em 1963.

4 Reuniões nas quartas-feiras, ao meio dia, realizadas ao longo de 27 anos em locais diferentes, onde Lacan tratava dos problemas cruciais da Psicanálise e se expunha em reflexões no limite de seu saber, ou seja, sem transmitir um saber já sabido.

5 Após um tempo em que reunia cerca de vinte pessoas em sua própria casa, passou a ocupar para tal o asilo de SaintAnne e, posteriormente, salas na École Normal Supérieure. 
Escola se dava pela constituição de um cartel. No cartel, a reunião de quatro membros em torno de uma temática atual da Psicanálise deveria fazer produzir em cada integrante um conhecimento singular - e, ao mesmo tempo, compartilhado com os demais - que permitisse avançar o conhecimento e a pesquisa psicanalíticos. Um analista mais experiente poderia ser chamado durante o processo para intervir na medida em que o trabalho se estagnasse por algum motivo. Essa seria conhecida como a função do +1 , um integrante do grupo que não ocuparia o lugar de professor, mas de analista, para intervir com sua escuta no processo de formação disparado pelo cartel. Ao final de no máximo dois anos, um cartel deveria dissolver-se e cada membro apresentar, no espaço público da Escola, suas produções (LACAN, 2003, p. 235).

Três anos após a fundação da EFP, surge a Proposição de 9 de outubro de 1967 (LACAN, 2003, p. 248-264) que institui, também como dispositivo de formação, o passe. O dispositivo do passe configurava uma articulação entre aquilo que se aprende a partir da experiência do inconsciente na análise pessoal e o que o saber psicanalítico pode produzir no campo teórico. Tratava-se da passagem, por meio do testemunho de dois analisantes acerca da experiência de análise de um aspirante a analista da Escola, para uma espécie de banca formada por analistas experientes, chamada tribunal do passe. Os passantes e o tribunal configuravam os alguns outros mencionados como o coletivo que autorizaria, além de si mesmo, um analista a nomear-se como tal. O passe era, portanto, o testemunho público de uma transformação, mas também um dispositivo de produção de avanços do saber psicanalítico e uma ex-posição ${ }^{6}$ de si.

Com isso, Lacan problematizou duas tendências presentes na formação psicanalítica da época: a tendência teoricista, ou seja, da epistemologia sem a clínica e, ao mesmo tempo, a tendência puramente pragmática, levada a cabo pelo fascínio do exercício de poder na relação transferencial em situação de análise.

Juntamente com seu Seminário, o cartel e o passe constituíam um projeto de formação de raízes diretamente plantadas no campo da experiência da Psicanálise. Lacan logrou reunir públicos diferentes na Escola e formar analistas advindos dos mais diversos campos do conhecimento. Sua pesquisa permitiu questionar e rediscutir concepções de doença mental, atribuindo uma nova condição subjetiva para os chamados doentes mentais. Seus achados possibilitaram o trabalho psicanalítico posterior com psicóticos e autistas, e mudaram o acento da clínica para a enunciação subjetiva dos pacientes ao invés da noção curativa de sintomas.

\section{A ESTÉTICA DO CORTE NA ESCOLA DE LACAN E NA FORMAÇÃO DO ANALISTA}

O psiquiatra Lacan se tornou psicanalista aos 52 anos de idade. Disse-o no momento em que julgou deixar de ser um leitor e disseminador das ideias de Freud para assumir uma posição crítica e, desse lugar, fazer avançar o saber ao qual estava filiado. A declaração de Lacan, autorizando-se psicanalista em um momento supostamente tardio em sua trajetória e defrontado com a necessidade de uma cisão com as ideias de seus colegas psicanalistas, faz refletir sobre o posicionamento ético acerca das propostas contemporâneas de formação de um modo geral.

A lógica da formação psicanalítica segundo a EFP parece sugerir uma ética educacional peculiar. $O$ ato analítico no contexto do ensino e da transmissão propõe, tanto àquele que ensina como ao que aprende, o que poderíamos chamar de uma constante ação problematizadora de si mesmo. Os dispositivos da Escola, como o cartel e o passe, são instituídos para garantir a pesquisa, a experimentação e o compartilhamento com o outro através do testemunho público de uma transformação, na qual alguém pode sustentar, apenas em seu nome, a posição de sujeito em relação ao saber que produziu. São dispositivos evidentemente instaurados para que ocorram atos emancipatórios reveladores de autonomia de pensamento - pouco comuns em instituições formadoras contemporâneas - e para que cada um possa tornar-se responsável pelo

\footnotetext{
${ }^{6}$ Essa grafia tem por objetivo, além de evidenciar o sentido comum de exposição contido no ato do testemunho público, indicar o descentramento egóico nessa experiência.
} 
que constrói. Trata-se de um modo de ensaiar-se, assim como na situação psicanalítica de tratamento, na qual o analisante deriva uma significação para si através de suportes doados pelo analista. Nela, cabe ao analisante decifrar seu desejo com o suporte das construções em análise para dar testemunho dele através de suas reconstruções subjetivas e reinvenções.

A produção de um novo significante deveria estar em jogo todo o tempo no percurso de uma formação. E o tempo, nesse caso, é algo sempre indefinido, especialmente porque a formação se dá através de um percurso em que o início, a trajetória e a chegada só podem ser definidos a posteriori. Portanto, se interessa a um determinado processo de formação a produção de um novo significante que represente o sujeito produção de diferença -, mais do que interessaria a produção de um profissional que saiba reproduzir os atos para os quais fora treinado; é fundamental que possa haver clareza sobre a necessidade de se falar do sujeito.

No contexto da Psicanálise, é apenas com Lacan que esse debate tornou-se possível. Para ele, muito antes de uma atribuição do indivíduo, o sujeito precisa ser entendido como aquilo que subverte convenções e sentidos fixos. Não é uma entidade com um significado cristalizado do qual podemos afirmá-la por meio da sua determinação no tempo e no espaço. Um sujeito é, em sua essência, um efeito significante.

A preocupação de Lacan com a introdução dessa noção foi, como costumava declarar, "formar psicanalistas que estejam à altura do sujeito" (LACAN, 2006, p. 53). Um sujeito decorrente da pesquisa clínica formal que revelou a Freud o inconsciente como aquilo que sonha, erra, ri e sofre à revelia da realidade consciente de um eu organizado estritamente pela razão. Ali está o sujeito, denunciado no momento da sua produção: a formação do inconsciente. Por seu efeito de subversão da lógica racional, é preciso concebê-lo precisamente como um sujeito cindido: o sujeito barrado. É assim que Freud já intuía uma definição de sujeito com o aforismo Wo Es war, soll Ich werden, impossível de ser interpretado rigorosamente desconsiderandose suas características reunidas no termo alemão Es, morada do sujeito, e uma sutileza da tradução do termo werden, advir, que, no alemão, carrega em si o alcance de crescimento no devir (LACAN, 2006, p. 93).

A elaboração acerca do sujeito traz consigo algo de essencial para as questões da formação. E parece também poder importar a outros contextos além da psicanálise, na medida em que a produção singular, inovadora, no âmbito dos demais campos de formação profissional seja buscada. Isso se torna uma premissa verdadeira se ao menos não estivermos interessados apenas na produção em série de identidades profissionais.

Não existem motivos sustentáveis para assumirmos que o estabelecimento de um novo significante, como, por exemplo, alguém enunciar-se psicanalista e ser reconhecido como tal, tenha um limite temporal estipulado, pois diz respeito ao percurso de uma possibilidade de enunciação.

A questão da enunciação leva a mais um aspecto fundamental. Como assinalado no item anterior, Lacan, em sua prática, manifestava uma confiança imensa nos efeitos psicanalíticos do sujeito do inconsciente, se este fosse devidamente escutado. Pautada na questão do desejo, ao invés do prazer, sua clínica era rigorosa em relação às descobertas freudianas após 1920 (FREUD, 1920/1976) e coerente com o que se revela a partir dos efeitos do sujeito nas formações do inconsciente. Escutar a produção discursiva do sujeito diz respeito às possibilidades enunciativas, e remete a questões da ordem da comunicação. A lógica do sujeito desfaz uma compreensão equivocada, pela qual a linguagem constituiria comunicação precisa e inequívoca entre interlocutores (LACAN, 1966/1998, p. 248 e segs.; LACAN, 2006, p. 94). O engano se dá no plano da intersubjetividade, ao se considerar erroneamente que o sujeito se confunde com a própria mensagem, tornando-se aquilo que passa de uma subjetividade à outra. Essa confusão, diz Lacan (2006), configura o pressuposto utilitário e reducionista segundo o qual a essência da linguagem é a precisa comunicação. 0 aparelho psicanalítico de pesquisa e de clínica nos revela o sujeito como a instância que faz falhar todo e qualquer esforço de circunscrição racional e lógica em qualquer campo de experiência. Portanto, Lacan objeta que, naquilo que o sujeito tenha a possibilidade de se fazer escutar através da fala, não consiste em que venha a afirmar-se, a definir-se, mas essencialmente em fazer-se reconhecer (LACAN, 2003, p. 142). Portanto, o que 
está em jogo na linguagem é, antes da função de comunicação, a enunciação, ou seja, o que define a posição do sujeito na fala.

Um dos principais argumentos da posição de Lacan a respeito da teoria psicanalítica emerge da necessidade de trabalhar considerando o sujeito em todos os âmbitos em que se manifeste, ou seja, onde haja vida e relação. $O$ crédito irrestrito que Lacan dava ao sujeito do inconsciente justifica-se pelo achado freudiano que revela o efêmero das estruturas lógicas racionais do Ego. Essa condição imposta pelos efeitos do sujeito torna clara a importância da pergunta pelo lugar enunciativo da fala, lugar onde se pode ler o desejo. É assim que parece tornar-se possível tomar a questão da produção de efeitos de singularidades no contexto das formações para o exercício de uma prática profissional, como tentar-se-á propor mais adiante.

René Major, num colóquio de 1999, intitulado Lacan Psicanalista, aponta para ao menos três possibilidades de reflexão sobre a suposta posição solitária de Lacan no ato de fundação de sua Escola em 1964 (DIDIER-WEILL, 2007, p. 213 e segs.). As duas primeiras apontam para a solidão do pesquisador de ponta, de qualquer área do conhecimento, que, em determinado momento de sua investigação, passa a não mais contar com seguidores ou colaboradores. Ao mesmo tempo, o pesquisador de ponta não desiste de seguir o caminho que sua reflexão indica, o que o torna solitário. Porém, ao assumir sua solidão, ele não se faz inativo e fixado a uma posição melancólica. A terceira proposta de Major refere-se a uma renúncia: estar só em sua própria relação com a causa que lhe diz respeito em seu fazer profissional é um aspecto sugestivo de um posicionamento ético, tanto da prática profissional do analista quanto das condições peculiares de sua formação. $O$ estar só em relação à psicanálise não deve ser tomado como condição apenas de Lacan, mas de todo analista que renuncia ao aval de uma titulação bancada por uma instituição.

Estar sozinho em relação àquilo que se construiu a partir da filiação a um campo de conhecimento é um posicionamento ético difícil de sustentar, mas libertador; tanto para o profissional quanto para o próprio avanço do conhecimento em sua área. Encontrar-se solitário em seu campo de conhecimentos é o que relançaria a todo profissional - logo após a cerimônia de formatura acadêmica - a seguinte pergunta: afinal, sua posição como suficiente portador do conhecimento de determinada área para exercer uma prática e receber em troca um pagamento de onde obtém sua possibilidade de subsistência, é uma construção que se sustenta pelos seus atos profissionais ou pela corporação a que pertence? Essa é a questão que a frase de Lacan acerca de sua solidão em relação à causa psicanalítica remete à formação e à prática do analista. Será que o problema ético lançado pela frase lacaniana só teria pertinência à profissão de analista? A questão do desejo no contexto de formação de outras profissões seria bem-vinda?

A última parte desse artigo está reservada para uma espécie de extensão da psicanálise: o lançamento inicial de um oferecimento daquilo que o tema da formação do analista e das propostas inovadoras da Escola de Lacan pode contribuir para uma questão a respeito da formação profissional superior em outras áreas de atuação.

\section{OS 'NÃO TOLOS' ERRAM}

Até aqui, dois aspectos retirados da proposta psicanalítica da Escola de Lacan foram ressaltados: (a) a consideração radical do sujeito no contexto da formação do analista; e (b) o dilema a respeito da sua prática ser sustentada pela construção singular de seu percurso e desejo de formação ou por uma instituição avalizadora.

O paradigma racionalista da filosofia - pedra angular da ciência alicerçada pelo logos e pelas exigências metódicas para a formalização do pensamento inequívoco - tende a descartar os efeitos do sujeito. A busca do conhecimento científico e da produção tecnológica como auxiliar das práticas humanas está colocada sempre no sentido da previsão dos fenômenos e minimização do erro. A ciência da administração de recursos e dos fluxos em uma instituição, organizados por meio de tarefas e funções bem desenhadas e definidas por um organograma, propõe classicamente que todo tropeço da máquina administrativa é devido ao chamado 
erro humano. Termo esse que, quando utilizado, serve de desabono à máquina e à instituição. Errar, no entanto, é humano. É a própria Psicanálise - embora não se aproxime de um humanismo - que nos ensina a não descartar o erro, mas tomá-lo na dimensão da equivocidade: uma escuta diferencial dos lapsos que revela uma novidade no contexto psicanalítico da clínica.

Pois bem, ao considerarmos uma instituição formativa atravessada pelo discurso científico, aquele que ao controlar variáveis tenta diminuir a possibilidade de erro, parece claro o banimento do sujeito em seus processos. Entretanto, em que medida a instituição acadêmica, ao excluir o erro, as incoerências de pensamentos, as rupturas paradigmáticas, a dialética e os diálogos, permite o surgimento de boas ideias ou sequer valorizar uma novidade frutífera? Não à toa, Lacan (1969-70/1992) propõe o discurso universitário como o laço social que produz sempre o mesmo: um sujeito barrado, advindo do trabalho repetitivo, agenciado pelos significantes organizados como um saber sustentados pelo mestre. É assim que uma instituição, quanto mais poderosa, menos espaços permite para ideias originais: quanto mais partidos marxistas estão fortalecidos no poder, menos estudos marxistas são produzidos e, quanto mais a igreja católica se solidificou, menos teólogos apareceram (CLAVREUL, apud DIDIER-WEILL, 2007, p. 23).

As propostas da Escola de Lacan para a formação de analistas - em especial o cartel e o passe, já mencionados - procuravam incluir no processo de formação a dimensão do sujeito como condição sine qua non. Os discursos universitário, do mestre e da histérica, preponderantes em instituições de ensino e formação, também eram organizadores da Escola de Lacan. Entretanto, a novidade dessa Escola foi tentar incluir o discurso do analista em seus processos formativos, único em que se poderia produzir um novo significante mestre; uma novidade no discurso, por meio do trabalho do sujeito barrado, agenciado pelo objeto causa de seu desejo.

Parece evidente que a consideração do sujeito e das formações do inconsciente no processo formativo seja razoável para o contexto da Psicanálise, devido ao tipo de objeto desse campo de saber. Entretanto, que outra área do conhecimento e de prática profissional prescindiria de meios de produzir novidades, inovações ou não seria beneficiada por contar em seu escopo com algo que subverte o dogma e permite a criação ou a inventividade?

Afirmava-se acima que o diploma de nível superior para a formação do analista era necessário, mas não suficiente. Isso marca uma condição que abre a possibilidade para qualquer profissional poder se tornar psicanalista, mas que não é suficiente, pois seria preciso o seu envolvimento na questão do desejo de ser analista, além do estudo e da prática clínica. Se tomarmos a mesma afirmação fora do contexto estrito a que se refere, parece que podemos seguir assumindo-a como pertinente. O diploma, obtido ao final de um percurso acadêmico, é a licença simbólica - e, portanto, socialmente aceita - para que um indivíduo passe a gozar das prerrogativas profissionais da área a partir do ritual da formatura. No entanto, o recém formado sabe de sua insuficiência para o exercício profissional imediato. E sua enunciação, como sujeito da profissão que escolheu, será um ato ético bem posterior à formatura, sustentado na experiência construída no tempo do exercício profissional, que já exerce pela diplomação.

A busca por pós-graduações e capacitações é o sintoma dessa insuficiência. Entretanto, essa formação complementar também costuma ser estruturada pela transmissão de informações e de instrumentalização técnica por meio dos mesmos dispositivos produzidos pelo discurso universitário, a saber, conteúdos organizados em disciplinas, frequência, créditos e produção a ser avaliada.

Em outro senso, a lógica da educação permanente propõe a possibilidade de resgatar as experiências do contexto do trabalho como estruturantes de uma aprendizagem, individual ou coletiva. Nela, o tempo de produção do trabalho é resgatado também como tempo de aprendizado a partir dos contextos e problemas específicos do fazer em determinada prática. Um programa de residência em área profissional da saúde, por exemplo, embora estruturado sobre as bases acadêmicas, se aproxima bastante da ideia de uma educação realizada no contexto da prática. 
Aprender a partir da realidade do trabalho é ter de inventar em ato, muitas vezes, modos de resolver problemas que extrapolam as situações didáticas utilizadas como treinamento, além das teorias. Perguntase: de que recursos se vale o profissional quando encontra uma situação prática que lhe excede em seu conhecimento, ainda que ocorra no contexto estrito de sua profissão? Como encontrou a solução ou que dilemas construiu em torno da situação que interroga sua formação? Por fim, como resgata para si ou compartilha essa experiência de potencial formativo para avançar o conhecimento teórico ou técnico de sua profissão?

São questões fundamentais a qualquer campo profissional, pois, a todo momento, no cotidiano das mais variadas práticas, ocorrem situações com potencial de formação que fogem de um currículo estruturado como tempo para aprender. Caso não sejam resgatadas em dispositivos que as acolham, tornam-se questões de foro privado e, tanto pior, não problematizado e teorizado para servir de avanço, transmissão de saber e compartilhamento coletivo na profissão. As cenas de formação - entendidas como surgimentos inesperados no tempo de aprendizagem ou de prática profissional, em que um sujeito emerge ali onde a informação e a técnica não tamponam a falta - constituem espaços e tempos privilegiados para a pesquisa e a produção de novidades em campos profissionais variados (MEDEIROS, 2016). No entanto, na lógica curricular, as cenas de formação são descartadas, ou porque não podem ser previstas no currículo, ou porque contradizem a teoria, ou, finalmente, porque não é costumeiro prever um dispositivo para acolhê-las nas propostas acadêmicas de formação.

Na formação psicanalítica, há a supervisão, também chamada de análise de controle, para marcar a diferença entre um olhar que corrige e um tipo de escuta que coloca em análise e responsabiliza o outro em seu ato profissional. Parece claro que o sentido comum da supervisão sustenta o imaginário de um espaço corretivo de onde se espera a resposta certa e o aprendizado por imitação. Aqui, novamente a exclusão do erro e a repetição dos cânones profissionais, apostas das epistemes científicas que estruturam as formações superiores em geral, se fazem presentes e funcionais. Na supervisão psicanalítica, o que opera é a interpretação que lança um enigma, cuja elaboração é de responsabilidade de quem realiza o ato analítico. Ato que não se sustenta pela corporação de psicanalistas e nem por um regimento interno que o garantiria.

Uma supervisão que corrige, embora a natureza de algumas profissões o exija, deixa de lado uma pergunta pelo erro, pelo desejo de ser profissional, pela possibilidade de produção de novidade. Opera na formação apenas no registro do treinamento de uma técnica a ser reproduzida.

Os cursos superiores, em tempos de propostas educacionais sem a pergunta acerca da construção de uma sociedade e a observação da diversidade cultural e política, têm se tornado cursos técnicos avançados nos quais a informação e o treinamento formam sujeitos acéfalos da profissão. $O$ gozo com o trabalho remunerado, promotor de uma espécie de dignidade capitalizada no contexto social, vela as questões do desejo e das necessidades nas escolhas e exercícios profissionais nos mais variados setores. Em qualquer campo profissional, não haver espaços de fala e indagação acerca do desejo pela profissão reduz os modos de agir ao mero exercício, ainda que eficiente, de uma técnica.

O que se entende por escuta psicanalítica excede em muito o exercício de uma técnica, pois é da ordem da incorporação de um saber e de uma ética. Trata-se de um saber que toma o corpo do analista, fazendo seu ouvido funcionar para além do órgão. Haveria ganho social, cultural e de qualidade de ofertas de serviços, se a lógica da teoria e técnica, que organiza as formações profissionais em nível superior, desse espaço ao par teoria e ética na produção das práticas?

Trata-se aqui de uma problematização importante em nossos dias. Atualmente, cada vez mais há a necessidade do desenvolvimento de características que excedem a técnica e a informação como capacidades que permitam ao profissional transcender seu restrito objeto de conhecimento, para que possa adquirir outras, como, por exemplo, o trabalho em equipe, a escuta e a disposição para abertura ao outro e a gestão de pessoas, entre outras, no contexto da integração de conhecimentos no campo do trabalho. Muitas dessas 
características, ao que parece, são da ordem da construção de um saber, mais do que uma capacidade técnica aprendida genericamente.

Os dispositivos e propostas da Escola de Lacan, ainda que restritas ao contexto da formação do analista, ao problematizarem o desejo pela formação e resgatarem as produções do saber inconsciente como verdadeiros achados de potencial criativo, parecem constituir analisadores e objetos de pesquisa potentes para quem se interesse pelo problema da formação profissional em diferentes campos.

A capacitação garantida pela informação e treinamento técnico, cuja prática seja sustentada no poder de uma corporação - mais do que no ato singular do profissional - e que reproduz um dogma sem diálogo com a sociedade e a cultura em que está inserida, está fadada ao anacronismo e à irrelevância. Ainda que o poder advindo da representação social de determinada profissão possa ser eficaz na manutenção de um status quo, seu potencial para o avanço de conhecimentos, assim como a pertinência de seus atos públicos, se empobrecem. Esse é um risco que a própria Psicanálise pode evitar ao seguir problematizando a formação do analista: uma cautela bem-vinda para que ela, assim como outros campos de conhecimento, se renovem junto ao processo histórico e social em que estão inseridos. E, também, para que se saiba mais acerca da construção de saberes em variados campos, especialmente aqueles que supõem suficientes apenas os exercícios das suas técnicas ou uso de tecnologias. Por fim, para que os profissionais esclarecidos de seu desejo pela filiação profissional escolhida possam, situados eticamente no laço social, exercer seu ofício ao invés de seu poder.

Recebido em: 2 de março de 2016. Aprovado em: 17 de dezembro de 2016.

\section{Referências}

DIDIER-WEILL, A.; WEISS, E.; GRAVAS, F. Quartier Lacan: testemunhos. Rio de Janeiro: Companhia de Freud, 2007.

DORGEUILLE, C. A segunda morte de Jacques Lacan. Porto Alegre: Artes Médicas, 1986.

FREUD, S. A dinâmica da transferência (1912) Rio de Janeiro: Imago, 1976. (Ed. standard brasileira das obras completas, 12).

Além do princípio do prazer (1920) Rio de Janeiro: Imago, 1976. (Ed. standard brasileira das obras completas, 18$)$.

Recomendações aos médicos que exercem a psicanálise (1912) Rio de Janeiro: Imago, 1976a. (Ed. standard brasileira das obras completas, 12).

Sobre o início do tratamento (novas recomendações sobre a técnica da psicanálise I) (1913) Rio de Janeiro: Imago, 1976. (Ed. standard brasileira das obras completas, 12).

Uma dificuldade no caminho da psicanálise (1917) Rio de Janeiro: Imago, 1976. (Ed. standard brasileira das obras completas, 17).

GIROUD, F et al. Lacan, você conhece? São Paulo: Cultura, 2002.

JORGE, M. A. C. Lacan e a formação do psicanalista. Rio de Janeiro: Contra Capa, 2006.

LACAN, J. Escritos (1966). Rio de Janeiro: Jorge Zahar, 1998.

Meu Ensino. Rio de Janeiro: Jorge Zahar, 2006.

O avesso da psicanálise (1969-1970). Rio de Janeiro: Jorge Zahar, 1992. (O seminário, 17).

. Os quatro conceitos fundamentais da psicanálise (1964). Rio de Janeiro: Jorge Zahar, 1988. (0 seminário, 11).

Outros Escritos. Rio de Janeiro: Jorge Zahar, 2003.

MARINI, M. Lacan: a trajetória do seu ensino. Porto Alegre: Artes Médicas, 1990. 
MEDEIROS, R. H. A, Residência integrada em cenas: ensaios críticos acerca da formação do profissional em saúde. 1. ed. Porto Alegre: Rede UNIDA, 2016. Disponível em: $<$ http://www.redeunida.org.br/editora/biblioteca-digital/serie-vivencias-em-educacao-nasaude/residencia-integrada-em-cenas-ensaios-criticos-acerca-da-formacao-do-profissional-emsaude-pdf/view>. Acesso em: $18 \mathrm{dez} .2016$.

ROUDINESCO, E. História da Psicanálise na França: a batalha dos cem anos 1925-1985. V. 2. Rio de Janeiro: Jorge Zahar, 1988.

Roberto Henrique Amorim de Medeiros

robertoamorim80@hotmail.com 